\title{
Carolina Maria de Jesus e a representação social de pobre em Quarto de despejo
}

\section{Carolina Maria de Jesus and the social representation of poor in Quarto de Despejo}

Miséria é miséria em qualquer canto, riquezas são diferentes.

(Arnaldo Antunes)

André Luis Gomes Moreira'

\begin{abstract}
Resumo
Este artigo discute contribuições da literatura para a representação do pobre a partir da análise da obra Quarto de Despejo, de Carolina Maria de Jesus. Toma-se como suporte teórico o conceito de representações sociais, desenvolvido por Serge Moscovici (2012). Para além de uma representação artística do autor sobre o objeto em estudo, mas sem, contudo, desmerecer o caráter estético da obra literária, discute-se neste texto o registro do pensamento social de uma época sobre o pobre, mais especificamente sobre o favelado brasileiro, a partir da análise do conjunto de crenças, imagens, metáforas e símbolos utilizados, evidenciando-se, em última instância, todo um pensamento socialmente partilhado quanto a esse objeto social. O estudo revela o estabelecimento de um perfil historicamente partilhado que delineia o pobre como alguém desprovido de seus direitos básicos de sobrevivência e de livreconcorrência na sociedade, condenado a viver em guetos sem infraestrutura, comumente associado à violência, vícios, fome, sujeira, mas que, por outro lado, revela consciência política manifestada por um discurso de resistência a assumir essa identidade social.
\end{abstract}

Palavras-chave: Literatura. Quarto de despejo. Representações sociais. Pobre. Consciência política.

Mestre em Literatura Brasileira pela Universidade de Brasília, onde também concluiu a graduação no curso de Letras Português. É professor de Literatura Brasileira e de Produção e análise de recursos didáticos no curso de Letras e de Língua Portuguesa em cursos diversos no Centro Universitário de Brasília UniCEUB. Tem interesse em pesquisas nas áreas de Literatura e representação, Metodologias de ensino de língua portuguesa e de literatura e Literatura infanto-juvenil.

\section{Abstract}

This article discusses contributions of literature to the representation of the poor based on the analysis of the work Quarto de Despejo, written by Carolina Maria de Jesus. The concept of social representations, developed by Serge Moscovici (2012), is taken as the theoretical support of the article. Apart from an artistic representation of the author on the object under study, but without disregarding the aesthetic character of the literary work, in this paper it is discussed the record of social thinking of an age on the poor, more specifically on the inhabitants of Brazilian slums, from the analysis of the set of beliefs, images, metaphors and symbols, demonstrating ultimately a socially shared thought on that social object. The study shows the establishment of a historically shared profile that outlines poor people as someone devoid of 
the basic rights of survival and free competition in society, condemned to live in ghettos without infrastructure, commonly associated with violence, addictions, hunger, filth, but, on the other hand, reveals political consciousness manifested by a discourse of resistance to assume that social identity.

Keywords: Literature. Quarto de despejo. Social representations. Poor people. Political consciousness.

\section{Contexto e problematização}

Apesar do que sugere a epígrafe, estudos sociológicos recentes relativos à pobreza estabelecem a distinção entre a pobreza socioeconômica e a pobreza política, sendo a primeira relativa "à carência material" e a segunda referente "à dificuldade histórica de o pobre superar a condição de objeto manipulado, para atingir a de sujeito consciente e organizado em torno de seus interesses" (DEMO, 1994, p. 19-20). Tal definição reconhece, o que já fizera Marx anteriormente, bem mais que a existência de uma segmentação da sociedade em classes sociais, mas a legitimidade de um extrato social historicamente desfavorecido.

Mais que uma definição, a pobreza é uma realidade e vários são os fatores que há muito têm contribuído para o crescimento de uma população reconhecidamente pobre no Brasil e no mundo. Dentre alguns desses fatores, pode-se citar a) a injusta distribuição de oportunidades vimento Humano (IDH). Esse índice substitui o Produto Interno Bruto (PIB) per capita como elemento indicador da condição socioeconômica dos países (riqueza ou pobreza), ao considerar, a partir de 1990, três indicadores sociais: escolaridade, expectativa de vida e renda associada ao poder de compra. Ao inserir o IDH em suas variáveis, a ONU concebe que será mais desenvolvida a Nação que proporciona condições dignas de vida traduzidas na longevidade dos homens, no acesso ao poder de compra e no acesso à educação.

Sobre as desigualdades sociais no Brasil, vale salientar que, no RDH - 1992: Dimensões Internacionais de Desenvolvimento Humano, o Brasil é apontado como o país que tem a pior distribuição de renda de todo o globo. Ao analisar a disparidade de renda entre os $20 \%$ mais ricos e os $20 \%$ mais pobres, constata-se que, enquanto a renda dos cinco mais ricos na Suécia é cinco vezes maior, seis vezes maior na Alemanha, nove vezes maior nos Estados Unidos, no Brasil, esse número é elevado a trinta e duas vezes. Além disso, no RDH - 2000: Direitos Humanos e Desenvolvimento Humano - pela liberdade e solidariedade, o Brasil é apontado como o $74^{\circ}$ país, bem atrás de Trinidad Tobago $\left(50^{\circ}\right)$, México $\left(55^{\circ}\right)$ e mesmo a Colômbia $\left(68^{\circ}\right)$, país onde impera o narcotráfico com todas as suas consequências sociais.

Mais assustador que essa cifra, contudo, é o processo de naturalização dessas diferenças sociais a partir do qual se lança mão para, até mesmo, tornar possível a convivência com tal disparidade. O pobre, normalmente visto a partir de um certo grau de distanciamento como sendo o outro, ou, pelo menos, o ainda pior do que eu (mas não eu, ainda), integra-se em nossas relações cotidianas através do desconforto, uma vez que anda na contramão dos valores da sociedade capitalista pós-moderna ao ser socialmente definido não pelo que é ou pelo que tem, mas pelo que não é ou pelo que não tem.

Representado como sinônimo de uma categoria social menor, muitas vezes não pelas perdas sociais das quais foi/é vítima/cúmplice, mas, frequentemente, pelo juízo de valor a que se atribui a seus comportamentos, atitudes, espaços, cultura, linguagem, não raro, o pobre é percebido como parâmetro de decadência social não desejada, materializando em si todo um pensamento relacionado a fracasso, privação, estagnação, indignidade. 
É importante destacar que, como alertado anteriormente, o disparate econômico evidenciado pelos relatórios de 1992 e 2000 não resulta de tomadas de decisões políticas de um determinado governo específico, mas origina-se de todo um encadeamento histórico-financeiro que remonta ao período colonial e que denuncia ainda hoje uma realidade injusta de má distribuição de renda.

Nesse contexto, cabe investigar se a representação de pobre também evoluiu com o passar do tempo, sobretudo, levando-se em consideração o aumento de fatores intervenientes na constituição da realidade de pobreza no Brasil (inchaço populacional, políticas públicas que priorizam o cumprimento de acordos com entidades internacionais, legitimação do consumismo exagerado imposto por uma mídia cada vez mais comprometida com o mercado global).

\section{A literatura e o fenômeno da representação}

Percebe-se, dentre tantos outros meios possíveis, que também a literatura pode favorecer com certa nitidez a investigação da representação do pobre. Por se construir/constituir historicamente, ela denuncia, por intermédio de vários mecanismos (como a voz do discurso, as temáticas, as caracterizações e as ambientações enfocadas, incluindo também, até certo ponto, o estilo do autor e o gênero literário), a representação de inúmeros objetos, dentre os quais o pobre.

Seria ingênuo, no entanto, conceber o ato de representar como correspondente a um ato eminentemente individual, uma vez que, em primeira instância, significa reapresentar um objeto ou realidade anteriormente definida em um contexto social, portanto, coletivamente apresentado. Isso fica claro, em termos de literatura, quando se compreende que os vários elementos, descrições, construções, comparações de um determinado conto ou romance, por exemplo, ao mesmo tempo em que constroem a tessitura lógica da trama, também caracterizam, ou melhor, registram, de certa forma, a maneira de pensar de uma época, com seus preconceitos e valores, sobre determinado objeto.

Em outras palavras, justifica-se a afirmação de que a representação de um dado objeto se constrói em um âmbito mais amplo que o individual porque, mesmo sendo verbalizados apenas pelo narrador ou por algum(ns) personagem(ns), as frases, as expressões, os silêncios, os comportamentos referentes ao pobre, tomado como objeto social, são construídos pelo narrador/personagem a partir de uma representação desse objeto anteriormente construída e partilhada pela sociedade (na qual autor/ narrador/personagem está/ão inserido(s)), a qual evidencia a ideologia, em geral dominante, vigente sobre ele naquela época.

Não se quer dizer, contudo, que o trabalho literário se limita ao simples registro das representações da sociedade sobre os inúmeros objetos que a compõem. Mas não se pode negar que o trabalho do autor na construção de personagens, de espaços, de enredos nasce enviesado pelas representações que ancoram a construção desses elementos.

Em O cortiço, por exemplo, típico romance social e de costumes, Aluísio Azevedo apresenta, seja por meio, sobretudo, da metáfora dos espaços físicos (sobrado de Miranda em oposição ao cortiço de João Romão), seja pela construção das personagens, uma série de considerações não restritas à obra, mas a um pensamento impregnado de juízo de valor quanto ao comportamento de pessoas, lugares e ocasiões, que norteavam as relações, as condutas, o pensamento positivista de toda a sociedade do século XIX.

Ao se resgatar historicamente o estudo dedicado às representações, identifica-se em Émile Durkheim o primeiro teórico a utilizar o termo, sob o conceito de representações coletivas. Compreendidas muito além de um simples somatório das representações individuais, as representações coletivas designavam o conjunto de conhecimentos comuns partilhados pela sociedade, o qual exerceria sobre o indivíduo uma espécie de coerção para atuar de determinada forma (WAGNER, 1998).

A partir do conceito de representações coletivas, apresentado em 1961 em seu livro A Psicanálise, sua imagem e seu público, Serge Moscovici desenvolveu uma teoria psicossociológica centrada no conceito de representações sociais. Enquanto para Durkheim, referindo-se ao conhecimento empírico e prático a partir de estudos relativos a objetos estáticos e irrefutáveis (religião, mitos, morte...), as representações coletivas eram compreendidas como entidades explicativas absolutas da realidade (ele defendia a natureza estática dos objetos sociais), Moscovici dedicou-se ao estudo do conhecimento do 
senso-comum (apropriação do saber científico, religioso, enfim, reificado ${ }^{2}$ nas práticas cotidianas) como definidor de identidades e como orientador das práticas sociais, postulando, ao contrário de Durkheim, a plasticidade dos objetos ${ }^{3}$.

Inscritas nas práticas cotidianas, as representações sociais correspondem a um dos mecanismos pelos quais o indivíduo ou confirma a configuração de um determinado objeto ou, por outro lado, torna familiares realidades e/ou conceitos com os quais não está familiarizado, funcionando na prática como um instrumento construtor de significação da(s) realidade(s) (pobre, pobreza, desigualdades sociais).

\section{Análise das representações sociais de pobre em Quarto de despejo}

Nesse contexto, ao se compreender as representações sociais como um mecanismo de leitura das realidades sociais e tendo-se constatado a relevância do legado literário para a constituição das sociedades e para o registro do pensamento social das várias épocas históricas, torna-se clara a possibilidade de aplicação dos conceitos e pressupostos da Teoria das Representações Sociais, de maneira mais aprofundada, a um romance. Nesse sentido, sugere-se Quarto de despejo, de Carolina Maria de Jesus, de 1960, visto que, ao se depurarem os elementos da representação social de pobre construída no romance a partir da investigação do conjunto de crenças, imagens, metáforas e símbolos utilizados, evidencia-se, em última instância, todo um pensamento socialmente partilhado quanto a esse objeto social, estruturado atualmente, de alguma forma, também a partir dessa representação.

A narrativa, bem mais que um registro autobiográfico, consiste no depoimento porta-voz de um grosso extrato social transgeracional da população brasileira.

\footnotetext{
2 Moscovici (2012) considera coexistirem na sociedade contemporânea duas classes distintas de universos de pensamento: o consensual e o reificado. O primeiro referese às teorias cotidianas construídas e partilhadas pelo senso comum, e o segundo, ao sistema de conhecimento outorgado pela própria sociedade a falar em nome da verdade. $\mathrm{Na}$ sociedade moderna, esse último corresponde à ciência.

3 As representações coletivas explicavam fenômenos estáticos. As mudanças na sociedade modificavam tais fenômenos, os quais não podiam mais ser explicados pela teoria durkeimiana. Assim surgiu a representação social.
}

A autora-protagonista, moradora de uma das primeiras favelas do estado de São Paulo, discorre sobre suas dificuldades na lida diária pela subsistência como catadora de papel, privada, como milhares de outros iguais, da possibilidade de acesso aos mais corriqueiros gêneros de consumo.

Não tão igual aos iguais, embora comungasse da realidade de fome e de miséria dos outros favelados, Carolina diferencia-se dos seus por uma série de elementos. A polidez dos costumes, a lucidez que orienta suas relações sociais, a resistência à não contaminação de maus comportamentos praticados pelos vizinhos, mas, sobretudo, a utilização da escrita como meio de comunicação com o mundo são características que a fazem ser vista de maneira diferenciada pelos próprios vizinhos, tomandolhe, inúmeras vezes, ora como mediadora de conflitos, ora como causadora deles.

Contudo, tomando-se o cuidado de não diminuir a dignidade com a qual epicamente enfrentava seus dramas pessoais e, muito menos, o registro do relato (que, para muitos, não é considerado literatura), vale destacar a representação social do pobre tão ricamente apresentada em Quarto de despejo, uma vez que a tônica da obra é a denúncia da exclusão social sob vários aspectos.

Carolina é uma favelada e, a começar pelo título, já antecipa, de alguma forma, que a narrativa (registrada em forma de diário em pedaços de papel e em restos de cadernos retirados do lixo) se delimita a um espaço físico não socialmente privilegiado. Revelando certo domínio da técnica literária, a autora reconstrói o espaço da favela baseando-se na imagem de um quarto de despejo. Em oposição à sede do governo, denominada pela autora/ personagem como a sala de visita, à prefeitura, percebida como a sala de jantar, e à cidade, tratada como o jardim, a favela é extremamente bem representada pela imagem do quintal ou do quarto de despejo onde é jogado o lixo da cidade de São Paulo: "E, quando estou na favela tenho a impressão que sou um objeto fora de uso, digno de estar num quarto de despejo" (JESUS, 1998, p. 36).

Espaço restrito à população economicamente nada privilegiada, a favela é lugar para se confinar o pobre, percebido como entulho social. É observado que, durante os dias relatados na compilação da obra, não houve trânsito de ricos no espaço da favela, a não ser em tempos de Natal para a distribuição de presentes - revelando a 
compreensão desse universo como lugar esporádico de filantropia.

A favela é descrita pela sujeira ("O meu sonho era andar bem limpinha, [...] Já me habituei a andar suja” (JESUS, 1998, p. 18)), pela falta de infraestrutura

\begin{abstract}
Na enchente de 49 morreu o Pedro Cardoso, filho de Dona Ida. Quando eu soube que o Pedrinho havia morrido afogado pensei na decepção que teve a sua avó que pedia água, água bastante para matar os favelados e veio água e matou-lhe o neto. (JESUS, 1998, p. 6)
\end{abstract}

como lugar de delinquência infantil ("O João perdeu os 11 cruzeiros que eu dei-lhe para ir no Rialto. Ele levava o dinheiro na carteira e foi com os meninos da favela. E alguns deles já sabem bater carteira" (JESUS, 1998, p. 90)), como espaço de contrastes de uma mesma realidade suburbana ("Os vizinhos ricos de alvenaria dizem que nós somos protegidos pelos políticos" (JESUS, 1998, p. 47)) e como sinônimo de doença social

Quando eu vou na cidade tenho a impressão que estou no paraizo. Acho sublime ver aquelas mulheres e crianças tão bem vestidas. Tão diferentes da favela. As casas com seus vasos de flores e cores variadas. Aquelas paisagens há de encantar os olhos dos visitantes de São Paulo, que ignoram que a cidade mais afamada da América do Sul está enferma. Com as suas úlceras. As favelas. (JESUS, 1998, p. 92).

A favela é representada como lugar destinado a subempregados, indivíduos excluídos do mercado de trabalho por não apresentarem domínio mínimo dos requisitos exigidos pela sociedade, como, por exemplo, o domínio do código linguístico.

Nesse sentido, como afirma Pierre Bourdieu (1996, p. 42), a língua, ao eleger uma oficialidade baseada em critério também social, denuncia que "os locutores desprovidos de competência linguística se encontram de fato excluídos dos universos sociais onde ela é exigida ou então se veem condenados ao silêncio", uma vez que o acesso às condições de estudo corresponde a melhores condições de sobrevivência.

$\mathrm{Na}$ favela, percebe-se que o pobre "não tem vez" por "não ter voz". Um dos episódios que ilustram essa assimetria comunicativa foi o ocorrido em um juizado de menores. Na ocasião, uma funcionária interrogava o filho de Carolina com uma linguagem particularmente vulgar, pretensamente a mesma da criança, apenas baseada no fato de ela ser favelada. Apenas um caso dentre tantos ou- tros em que fica evidente o desprezo pela voz popular ("A voz do pobre não tem poesia” (JESUS, 1998, p. 156)), a qual não apresenta ressonância nem mesmo quando respaldada pelo poder financeiro ("Voltei para a favela furiosa. Então o dinheiro do pobre não tem valor? Hoje eu vou escrever e vou chingar a caixa desgraçada do Açougue Bom Jardim. Ordinária!” (JESUS, 1998, p. 168)).

Compreendida como símbolo da descartabilidade que distingue a sociedade de consumo ao se verificar refém do lixo e da cristalização dos papéis sociais, Carolina, não por ser a autora/personagem, mas por representar a personagem letrada da favela, é quem possui voz para denunciar as injustiças sociais daquele sistema, sendo reconhecida como a locutora legítima para chamar a polícia em casos de brigas.

Por meio da escrita, percebe-se um movimento constante da personagem de luta contra o nivelamento sociocultural em relação aos demais favelados. O certo domínio da escrita, adquirido muito mais pelas leituras do que pelo pouco tempo de escolarização, confere-lhe identidade diferenciada ao longo da narrativa, ao mesmo tempo em que denuncia, até mesmo por si, que a continuidade dos estudos, o hábito da leitura e da escrita, enfim, o trânsito a um estágio cultural socialmente mais valorizado não corresponde a uma regra na realidade do pobre, mas a uma exceção.

É sobretudo pela oposição de elementos, ora pelas características resistentes de Carolina, ora pelas características conformistas dos outros favelados, que se manifesta a representação social de pobre no livro. Apesar da postura diferente diante da pobreza, pela realidade partilhada, a personagem se distingue, mas continua engrossando o número daqueles por ela denominados Zé Povinho. Ressalta-se o discurso elitista embutido nessa alcunha, uma vez que destaca o caráter pejorativo e não carinhoso concernente à expressão.

De acordo com Celso Sá (1993, p. 28):

$\mathrm{Na}$ perspectiva psicossociológica de uma sociedade pensante, os indivíduos não são apenas processadores de informações, nem meros 'portadores' de ideologias ou crenças coletivas, mas pensadores ativos que, mediante inumeráveis episódios cotidianos de interação social, produzem e comunicam incessantemente suas próprias representações e soluções específicas para as questões que se colocam a si mesmos. 
Sendo assim, observa-se no contraste estabelecido entre o comportamento de Carolina e o dos demais favelados, a dupla face de uma mesma realidade, compondo o fenômeno denominado por Moscovici (2012) de representação social: o conjunto de conceitos, afirmações e explicações pelos quais informalmente se procede à interpretação e à construção das realidades sociais.

Dessa forma, todos os elementos figurativos e/ ou explicativos atribuídos ao pobre e a seu universo, seja por Carolina, seja pelos demais favelados, compõem a representação social de pobre, podendo-se justificar a diferença na conduta de ambas as partes pelo fato de os elementos centrais das respectivas representações serem diferentes $^{4}$. Moscovici (2012) postula que as representações orientam as práticas sociais e, por sua vez, as práticas denunciam as representações sociais nelas interferentes. Sendo um só objeto (pobre), as condutas de Carolina e as de seus vizinhos são distintas pelo fato de o objeto ser representado de maneira ímpar pelas partes, embora um substrato comum seja partilhado por ambos os lados. Para a personagem, o convívio com uma família culta e o exercício da escrita seriam elementos suficientes para autorizá-la a apossar-se do "discurso da classe média" como distinção em relação aos outros “Zé Povinho”.

Definido positivamente como autônomo, o pobre representado em Quarto de despejo não tem direito ao descanso ("Saí indisposta, com vontade de deitar. Mas, o pobre não repousa” (JESUS, 1998, p. 8)), uma vez que não tem garantido o mínimo diário para a subsistência, tampouco as garantias da lei. Portanto, vê-se condenado a uma realidade cíclica de sublimações por causa do trabalho ("Parece que vim ao mundo predestinada a catar. Só não cato a felicidade" (JESUS, 1998, p. 89)).

Em decorrência da má qualidade de vida, Carolina associa a vida do pobre à vida primitiva ("Devido ao custo de vida, temos que voltar ao primitivismo. Lavar nas tinas, cozinhar com lenha.” (JESUS, 1998, p. 69)) e animal ("O custo de vida nos obriga a não ter nojo de nada. Temos que imitar os animaes." (JESUS, 1998, p. 124)), características que geram identidade, sobretudo, quanto aos atos violentos e hostis na disputa por água, alimento e compreensão do compartilhamento de espaços públicos ou privados ("Quando alguém nos insulta é só falar que é

4 A esse respeito, consultar MOLINER, 1996, p. 51-78 da favela e pronto. Nos deixa em paz. Percebi que nós da favela somos temido" (JESUS, 1998, p. 91)).

Nesse contexto, a autora define certa vez a favela como "o chiqueiro de São Paulo" (JESUS, 1998, p. 199) e a si mesma como "um rato" (JESUS, 1998, p. 135) ao comparar sua realidade social à realidade dos ricos. Não se pode deixar de levar em consideração que ela acumula características peculiares ao estereótipo da mulher pobre: mãe solteira, negra, semianalfabeta, catadora de papel, não autorizada, portanto, a falar em nome dos ricos ou sobre eles.

As relações familiares, por sua vez, retratam o pobre como pertencente a uma família, em geral, numericamente não planejada, onde o homem nem sempre é reconhecido como o provedor e onde a mulher, na ausência ou omissão do companheiro, assume financeiramente as despesas da casa sem, contudo, deixar de ser submissa a ele

\begin{abstract}
Mas os homens da favela alguns vão trabalhar. Os outros quando não trabalham ficam na favela" (JESUS, 1998, p. 77)

Quando eu voltava fiquei olhando os homens da favela. A maioria não trabalha as segundas-feiras [...] Jesus (JESUS, 1998, p. 91)

Pensei no Alexandre porque ele não precisa pensar no trabalho. Porque obriga a esposa a pedir esmola. Ele tem uma filha: a Dica. A menina tem 9 anos. Ela pede esmola de manhã e vai para a escola a tarde (JESUS, 1998, p. 108)

Elas tem marido. Mas, são obrigadas a pedir esmolas. São sustentadas por associações de caridade (JESUS, 1998, p. 12) ${ }^{5}$.
\end{abstract}

O homem pobre é representado na obra inscrito em um contexto de ócio e vícios, enquanto a mulher é envolta em um ambiente violento, sendo-lhe negados o direito à individualidade (pelos filhos) e o direito à privacidade (pelo marido). Além disso, são corriqueiras as confusões de papéis familiares, sendo comuns casos de adultério, pedofilia, incesto, prostituição e alcoolismo infantis.

O soldado Flausino disse-me que a C. era amante do pai. Que ela havia dito que ia com o pai e ganhava 50 cruzeiros", (JESUS, 1998, p. 126)

Eu fiquei horrorisada quando ouvi as crianças comentando que o filho do senhor Joaquim foi na escola embriagado. É que o menino está com 12 anos (JESUS, 1998, p. 157).

\footnotetext{
5 Não se pode desconsiderar, contudo, que é uma mulher quem narra e a sua própria história. Atente-se ao fato de que o prisma do olhar feminino da escritora enviesa a representação do homem.
} 
A violência é uma constante no cotidiano da vida da personagem, revelando-se como um forte elemento constituinte da representação de pobre. Um episódio em que a Vera Cruz invade a favela para filmar as proezas de um delinquente que nem mesmo fazia parte da favela de Carolina ilustra a representação social de pobre já veiculada naquela época, concebendo-o como contraventor e a favela como lugar de bandidos. Dentre tantas outras realidades destacáveis nos ambientes pobres, parece que a violência se sobressai como elemento definidor das práticas sociais do pobre quando representado por um observador de fora, realidade que ainda hoje se repete ("O Bonito veio ver a filmagem. Perguntei-lhe se já foi filmado, porque ele é cantor: - Não, porque não sou popular" (JESUS, 1998, p. 212)).

Mas, em Quarto de despejo, nenhum elemento é mais central na representação social de pobre que a fome. Apresentada como elemento promotor ora de solidariedade pela partilha de alimento, ora como causadora de conflitos entre os vizinhos, a fome é a variável que sintetiza a realidade do pobre favelado que até então se distinguia por idiossincrasias periféricas, como escolarização (alfabetizado/analfabeto), moradia (alvenaria, madeira, papelão), profissões (lavadeira/catadora/soldado/açougueiro): "Não sei como havemos de fazer. Se a gente trabalha passa fome, se não trabalha passa fome" (JESUS, 1998, p. 143).

Tomada como elemento identitário ("Morreu um menino aqui na favela. Tinha dois meses. Se vivesse ia passar fome" (JESUS, 1998, p. 138)), ela é o elemento que une a diversidade da favela, justificando, até certo ponto, toda a dinâmica daquele ambiente: "tenho fome, por isso cato papel" - Carolina; "tenho fome, por isso não posso trabalhar" - alguns favelados; "eles têm fome, por isso preciso assisti-los" - Serviço Social, ou, ainda, "eles têm fome, por isso preciso fazer promessas" - políticos.

Dentre os elementos intertextuais apreendidos no romance, encontra-se bem forte o poema $O$ bicho, de Manuel Bandeira. Dessa vez, não sendo um outro a relatar o grotesco de ver um terceiro recorrendo ao lixo como alimento, mas o relato sóbrio daquela que se observa e se repugna digerindo os restos que lhe couberam pela injusta distribuição de renda e pelos abismos das diferenças sociais.

Incomodada continuamente pela fome, assim como Rodrigo S. M. o era por uma constante dor de dente em A hora da estrela, a autora/personagem corre na contramão da cultura elitista dos anos 60, procurando alcançar pela escrita o resgate de sua dignidade humana: "É preciso conhecer a fome para saber descrevê-la”, (JESUS, 1998, p. 27).

A fome é o eixo condutor da narrativa e, porque se repete, é o elemento que constrói a estrutura repetitiva do texto, uma vez que a história circula no mesmo contexto de fome e de favela. No entanto, não é esse o motivo do livro, mas a necessidade de investimento em educação, conforme esclarece a personagem/autora: "Os próprios favelados falam que favelado não tem educação. Pensei: vou escrever" (JESUS, 1998, p. 133).

Embora espacialmente circunscrita a uma realidade de estagnação, Carolina Maria de Jesus se antecipa em relação aos seus pela consciência política demonstrada ao longo de todo o romance ${ }^{6}$. Pedro Demo (1994) alerta que a pobreza política de não perceber porque se é pobre se revela mais degradante que a própria pobreza material, uma vez que promove a passividade e a submissão em oposição a possibilidades criativas de existência. Aos grupos sociais alienados pelas ideologias dominantes, sobram-lhes a observância dos códigos decifráveis sobre o que pensar, o que comer, o que fazer e não fazer, o que sentir, em quem votar, a quem adorar, o que ser e, sobretudo, em tempos de globalização, o que consumir.

Ao desenvolver conceitos de pobreza política, o autor evidencia a incapacidade de autogestão humana de um povo incapaz de criar seu próprio projeto de desenvolvimento (DEMO, 1992). Sendo assim, a historicidade, capaz de gerir e influir sobre o destino, diferencia as sociedades em termos de qualidade política definindo que, quanto mais consciente do papel de ator social, mais próximo se encontra o indivíduo da emancipação, construtora e recriadora de cotidianos mais dignos (DEMO, 1996).

Essa consciência política, aflorada na protagonista, mas diluída no resto das personagens (talvez por um capricho da autora de desejar um destaque nesse sentido em relação aos outros), parece confirmar os postulados

\footnotetext{
6 "O que o senhor Juscelino tem de aproveitável é a voz. Parece um sabiá e a sua voz é agradável aos ouvido. E, agora, o sabiá está residindo na gaiola de ouro que é o Catete. Cuidado sabiá, para não perder esta gaiola, porque os gatos quando estão com fome contempla as aves nas gaiolas. E os favelados são os gatos. Tem fome" (JESUS, 1998, p. 33).
} 
de Demo (1992) ao se verificar historicamente que muitos dos males que assolavam aquela comunidade ainda subsistem atualmente (desemprego, miséria, fome, enchentes, exclusão sociocultural...).

$\mathrm{Na}$ análise realizada por Demo sobre o RDH Brasil (1996), é relevante o alerta quanto à redução da pobreza absoluta e quanto ao aumento da pobreza relativa. Para o sociólogo, é claro que, em termos absolutos, com a evolução econômica e tecnológica, ricos e pobres melhoraram suas condições de vida ao longo dos anos (isso pode inclusive ser facilmente constatado nos relatórios internacionais). Apesar disso, os ricos sempre crescem vertiginosamente mais rápido em relação aos pobres, aumentando a desigualdade entre as classes sociais e, consequentemente, a pobreza relativa.

A representação social de pobre construída em Quarto de despejo evidencia a pluralidade de idiossincrasias relativas a esse objeto. Contudo, corrobora o estabelecimento de um perfil historicamente partilhado que o delineia como alguém desprovido de seus direitos básicos de sobrevivência e de livre-concorrência na sociedade, condenado a viver em guetos sem infra-estrutura, comumente associado à violência, vícios, fome, sujeira. Enfim, um entulho social que não deixa de ter seu lugar no mundo (o quarto de despejo), desde que não o ultrapasse.

Em 28 de maio de 1959, a autora sintetiza seu dia no registro de que:

\begin{abstract}
A vida é igual um livro. Só depois de ter lido é que sabemos o que encerra. E nós quando estamos no fim da vida é que sabemos como a nossa vida decorreu. A minha, até aqui, tem sido preta. Preta é a minha pele. Preto é o lugar onde eu moro. (JESUS, 1998, p. 186).
\end{abstract}

A imagem da vida como um livro revela-se esclarecedora da falta de consciência de grande parcela da população pobre brasileira quanto a sua vida, seus direitos, seus deveres, enfim, sua identidade, uma vez que a maioria é analfabeta.

Talvez tenha sido a partir desse trecho que nós brasileiros aprendemos o ditado de que "A coisa está preta!", quando a situação vivida parece difícil de melhorar. Ou, ainda, talvez o paralelismo construído por Carolina quanto à vida preta decorra de uma representação ainda mais antiga de que pobre seja negro ou de que, ao contrário, o negro tenha que ser pobre.

\section{Considerações finais}

A partir do exposto, percebe-se que, em pleno século XXI, parece que a representação social de pobre, acrescida de alguns elementos periféricos (maior acesso à educação básica e a tecnologias), não sofreu grandes modificações em relação à forjada na década de 1960 via Quarto de despejo. Ao contrário, os novos elementos acrescidos nessa violenta luta de classes (a atual tendência de romper barreiras geográficas, culturais, políticas e de estado através de tecnologias, como a internet, e do capital financeiro das bolsas de valores, transnacionalizando demandas e ofertas) têm trazido sérias repercussões negativas para os países pobres, corroborando velhos conhecidos da população marginalizada: desemprego, exclusão social e aumento da desigualdade social.

O fato é que, desde 1960, ou ainda, desde meados do século XIX, como em $O$ cortiço, o pobre sofre injustiças e se desfigura geração a geração, fatos esses que lhe imprimem rosto e identidade:

Dizem que o Brasil já foi bom. Mas eu não sou
da época do Brasil bom...Hoje eu fui me olhar
no espelho. Fiquei horrorizada. O meu rosto é
quase igual ao de minha saudosa mãe. E estou
sem dente. Magra. Pudera! O medo de morrer
de fome! (AZEVEDO, 2000, p. 195).

Contudo, embora a tomada de consciência quanto aos elementos construtores e significantes de nossa realidade seja uma forma de interferirmos no mundo à nossa volta, isso apenas não basta para o modificarmos. A representação social pressupõe atividade do grupo que negocia elementos da pobreza; no entanto, essa atividade mostra-se frágil e insuficiente para libertar-nos dessa situação, uma vez que a representação, ao criar identidades, reitera e confirma ainda mais a condição do pobre.

\section{Referências}

AZEVEDO, Aluísio. O cortiço. São Paulo: Ática, 2000.

BANDEIRA, Manuel. Estrela da vida inteira. Rio de Janeiro: Nova Fronteira, 2011.

BOURDIEU, Pierre. A produção das trocas linguísticas. In: _. A economia das trocas linguísticas. São Paulo: Edusp, 1996. p. 7-28.

DEMO, Pedro. Combate à pobreza. Campinas: Autores Associados, 1996. 
DEMO, Pedro. Pobreza política. São Paulo: Cortez, 1992.

DEMO, Pedro. Política social, educação e cidadania. Campinas: Papirus, 1994.

JESUS, Carolina Maria de. Quarto de despejo. São Paulo: Ática, 1998.

LISPECTOR, Clarice. A hora da estrela. Rio de Janeiro: Francisco Alves, 1990.

MOLINER, Pascal. La structure des représentations sociales. In: Images et représentations sociales. Grenoble: PUG, 1996. p. 51-78. Capítulo traduzido por Ângela Maria de Oliveira Almeida, Carmem Jansen de Cárdenas e Maria Stela de Campos Franca, com colaboração de Adriana Giovoni. Instituto de Psicologia da Universidade de Brasília.
MOSCOVICI, Serge. A Psicanálise, sua imagem e seu público. Petrópolis: Vozes, 2012.

SÁ, Celso Pereira de. Representações sociais: o conceito e o estado atual da teoria. In: SPINK, M. J. (Org.). O conhecimento no cotidiano. São Paulo: Brasiliense, 1993. p. 19-45.

WAGNER, Wolfgang. Sócio-gênese e características das representações sociais. In: MOREIRA, A. S. P.; OLIVEIRA, D. C. (Orgs.) Estudos interdisciplinares de representação social. Goiânia: AB, 1998. p. 3-20. 


\section{Para publicar na revista}

Universitas Humanas,

acesse $o$ endereço eletrônico www.publicacoesacademicas.uniceub.br. Observe as normas de publicação, para facilitar e agilizar o trabalho de edição. 